\section{La Didáctica de} la Literatura en Colombia:

\section{Un caleidoscopio en construcción}

\section{Didactics of literature in Colombia:} A kaleidoscope in construction

O ensino da literatura na Colômbia: A construção de um caleidoscópio

\section{Mónica Moreno Torres* Edwin Carvajal Córdoba*}

* Magíster en Literatura Colombiana, y candidata a doctora del Doctorado en Educación, Línea Didáctica Universitaria, de la Facultad de Educación de la Universidad de Antioquia. Profesora de la Facultad de Educación de la Universidad de Antioquia y miembro del grupo de investigación Didáctica de la Educación Superior (DIDES).

Correo electrónico: luna3910@hotmail.com

** Doctor en Teoría de la Literatura y el Arte y Literatura Comparada de la Universidad de Granada, España. Profesor de la Facultad de Comunicaciones de la Universidad de Antioquia. Coordinador del Doctorado en Literatura de la Universidad de Antioquia y miembro de los grupos de investigación Estudios Literarios (GEL) y Didáctica de la Educación Superior (DIDES).

Correo electrónico: ecarvajal@catios.udea.edu.co

\section{Resumen}

El concepto de caleidoscopio proviene del griego kalós -bella- , éidos -imagen- y scopéo -observar-. Esta triada "imagológica" permite sustentar cómo al analizar algunas concepciones de la didáctica de la literatura en Colombia aparecen diversas relaciones y enfoques de esta disciplina en construcción. Sus tonalidades y énfasis ponen en movimiento singulares preguntas que quedaran esbozadas en el presente artículo.

\section{Palabras clave}

Didáctica de la literatura, formación de docentes, formación de maestros investigadores.

\section{Abstract}

The concept of kaleidoscope comes from the Greek words: kalós-beautiful-, éidos-image-, and scopéo-to observe-. This "imago-logical" triad permits to hold how at the moment of analyzing some conceptions of didactics of literature in Colombia diverse relations and approaches of this discipline in construction are revealed. Their tonalities and emphasis put in movement remarkable questions that will stay outlined in this article.

\section{Key words}

Didactics of literature, teacher education, researcherteachers education

\section{Resumo}

O conceito de caleidoscópio vem do grego kállos, beleza + eîdos, o que é visto, imagem + -scópio. Esta tríade "imagiológica" permite descobrir varias relações e abordagens desta disciplina em formação depois analisar as concepções do ensino da literatura na Colômbia. As suas tonalidades e a sua ênfase despertam diversas questões insinuadas neste artigo.

\section{Palavras-chave}

Ensino de literatura, formação de professores, formação de professores pesquisadores.

Fecha de recepción: 31 de marzo de 2010 Fecha de aprobación: 11 de septiembre de 2010 teórico de una estrategia didáctica semio-epistemológica basada en la teoría de la abducción y la recepción estética de la obra literaria para la formación de maestros investigadores en la educación superior" adelantada por Mónica Moreno Torres, en el marco de sus estudios doctorales en el Doctorado en Educación de la Universidad de Antioquia. Investigación asesorada por el doctor Edwin Carvajal Córdoba.
Pedagogía y Saberes No.33. Universidad Pedagógica Nacional. Facultad de Educación. 2010, pp. 99 - 110 


\section{Introducción}

L a didáctica de la literatura en Colombia presenta diferentes desarrollos que se hacen evidentes en los modos, las formas, los énfasis y los enfoques presentados por los maestros de literatura y los investigadores en este campo. En efecto, para Vásquez (2005) uno de los aspectos que ha motivado en el país la realización de seminarios y coloquios acerca de las didácticas de las lenguas y de la literatura ha sido el predominio de asignaturas y referentes académicos relacionados con la lingüística, la historia de la literatura y las ciencias del lenguaje; a diferencia de la pedagogía y la didáctica de la literatura que han contado con un relativo bajo número de eventos académicos en el ámbito educativo nacional.

Desde tal premisa, este texto configura tres momentos: una reflexión relacionada con la didáctica de la lectura literaria en Colombia, una exposición del lugar de la literatura en el currículo, sin dejar de lado su relación con la formulación de estrategias de lectura y escritura literaria, y, finalmente, una disertación en la cual se ubica la didáctica de la literatura en la perspectiva de la formación de un maestro investigador en el campo propio de la lengua y la literatura.

Este último aspecto se convierte en el punto de articulación de las reflexiones que le preceden. Es decir, se intenta demostrar que una lectura comprensiva de los diversos enfoques y énfasis sugiere algunas pistas que nos pueden conducir a pensar la práctica pedagógica del maestro de literatura como un proceso de investigación de carácter abductivo y hermenéutico. Esta intención, además de enriquecer su labor en la escuela -al tener en cuenta su capacidad de creación e imaginación propia de su vivencia con los textos literarios-, cualifica la investigación en didáctica de la literatura al problematizar las relaciones entre la docencia y la investigación con propósitos formativos y estéticos.

\section{Hacia una didáctica de la lectura literaria}

De acuerdo con Cárdenas (1998a) en la última década del siglo XX se produce una ruptura epistemológica en los estudios del lenguaje al ser mirados, analizados y comprendidos a partir de sus vínculos con los problemas del conocimiento y de la interacción social ${ }^{1}$.

1 A continuación se sintetizan tres artículos del profesorinvestigador Alfonso Cárdenas Páez: "Pensar bien para leer mejor. Pedagogía de la lectura”, "Argumentación, interpretación y competencias de lenguaje" e "Implicación, inferencias y competencias de interpretación". Los dos primeros hacen
Esto es, los niveles lógico, analógico del sentido, los signos, los códigos y la pluralidad de textos se resignifican como producto de los desarrollos de las teorías del discurso en sus diversas variantes (dialogismo, polifonía, interdiscurso, antidiscurso). Este cambio replantea la mirada estratégica que distinguía a la didáctica de la lengua y ubica en su lugar una pedagogía del lenguaje. Este giro considera el lenguaje como una disciplina científica interesada en preguntarse por el lugar del sentido en relación con su naturaleza teórica, epistémica, metodológica y técnica.

En este cambio la inferencia ocupa un lugar primordial, pues propone superar la idea de la lectura como alfabetización o decodificación; en especial, por la participación del sujeto en la construcción del sentido del texto mediante la apropiación discursiva de la palabra escrita. La producción de sentido del texto se convierte en un mapa que el lector debe recorrer con la ayuda de algunas estrategias de lectura que lo lleven a tal producción.

Adquirir estas estrategias significa apropiarse de proyectos y trayectos de lectura. El proyecto, como exploración y construcción de sentido, lo lleva a moverse entre lo lógico y lo analógico, lo azuza a interrogar el texto para tener un dominio sobre el juego conjetural que lo acerca a la interpretación, y esta última lo motiva a la producción de su propio texto. De esta manera, el sujeto establece un pacto enunciativo con el discurso leído y el leído por otros; éste y aquél se convierten en partícipes del juego intersemiótico y en sujetos dialogantes.

Este juego, entre lo dicho y lo oculto, produce un vacío o una laguna que el lector esclarece cuando en su comunicación literaria diferencia el uso y el empleo de la lengua. En la primera modalidad, la lengua se entiende como significación; y, en la segunda, el sentido se constituye en un valor cultural de corte hermenéutico que moviliza la triada lector-texto-contexto de la obra. En tal proceso, los prejuicios del lector son determinantes para otorgarle sentido a la obra.

Este enfoque interactivo de la lectura también ha sido estudiado por Jurado (2000), quien adelanta una investigación en la ciudad de Bogotá con el propósito de caracterizar los modos de leer de los docentes para determinar si existe alguna relación entre sus potencialidades y dificultades con las formas de leer y las maneras de escribir de sus estudiantes.

Como punto de partida, les propone leer el cuento "Una mujer amaestrada" de Juan José Arreola por considerar su título provocador, abierto a su hori-

parte de la investigación que el profesor realizara en 1998, el segundo trabajo corresponde a otra de sus investigaciones culminada en el año 2000. 
zonte de expectativas como lectores e igualmente tapizado de trampas. Después de realizada la lectura, los docentes adelantan de manera individual un comentario escrito del cuento. Uno de los primeros resultados que llama su atención se relaciona con las diferencias entre el uso y la interpretación del texto. Es decir, una parte del grupo evita interactuar con el texto, otros establecen un proceso de interpretación. Así, en el primer grupo algunos describen comentarios personales, otros acuden al uso de tecnicismos a y citas de autoridad de manera indiscriminada, en un intento por escamotear el texto; así se alejan de la construcción del sentido. No obstante, otros maestros "sí logran dar el paso hacia abducciones creativas (lecturas en el ámbito crítico e intertextual)" (Jurado, 2000, p. 7).

El autor, a modo de conclusión, dice que la "falta de contacto con la escritura constituye un factor que ha influido en la calidad de las lecturas, tanto en profesores como en estudiantes" (p. 5). Asimismo, una prosa como la de Arreola promueve la formación de maestros (y estudiantes) dispuestos a identificar las trampas del relato. En palabras de Jurado, quien se inspira en Ricoeur (1996), “[...] el narrador no digno de confianza se propone modificar las expectativas del lector al empujarlo por una cuerda floja en el universo de la incertidumbre y burlarse de su fe ciega en el decir de los narradores, cuando en lo dicho hay sentidos contrarios. Pero en eso consiste el juego de Arreola, como el de Borges: necesitan un lector ingenuo, que luego se transforme de ingenuo en meticuloso para poder descubrir ese juego y así vivenciar el asombro de la interpretación textual" (Jurado, 2000, p. 3).

Como se puede observar, Jurado pasa de las "abducciones creativas de los profesores a los procesos de lectura, incertidumbre y escritura de los estudiantes" (1995, p. 45). En otro de sus textos, Jurado se propone identificar el tipo de enfoques que utilizan los profesores a la hora de evaluar los procesos de lectura y escritura de los estudiantes de educación básica.

Después de analizar una serie de evaluaciones en las que se "intenta" valorar la comprensión lectora del estudiante, concluye que en dichas pruebas la respuesta está dada; en consecuencia, el estudiante no tiene que adelantar un proceso de comprensión e interpretación del texto. En estos casos se trata de una habilidad nemotécnica en la cual predomina la arbitrariedad del evaluador, en tanto, como diría Larrosa, se controla el sentido del texto.

En este tipo de pruebas el sentido, al no ser construido, tampoco es interrogado y mucho menos interpretado. De igual modo, el lugar de los saberes que moviliza el texto, en relación con el horizonte de expectativas del lector, se pierde. Se trata, entonces, de prácticas de lectura autoritarias donde la eficacia se pone por encima de la conciencia del maestro/ lector.

Una manera de superar estas dificultades consiste en entender la lectura y la escritura como una aventura cognitiva; por tanto, como proceso abductivo. Desde esta perspectiva, la lectura abductiva incluye las reacciones afectivas y sensitivas de quien hace la abducción. En este proceso el lector debe estar en condiciones de describir las deducciones, las inferencias y las abducciones que le permitieron bucear en el texto. El primer razonamiento explica el juego de probabilidades; el segundo, analiza las pruebas que lo llevaron a la formulación de la hipótesis; y en la abducción del juego proposicional, surge la predicción -de tal conjetura y de ese movimiento emerge el descubrimiento de una nueva idea que se convierte en una abducción creativa-.

La lectura abductiva también ha sido abordada por Vélez, quien expresa que "la abducción proporciona al lector el saber conjetural que luego la inducción y deducción verifican" (1996, p. 18). Este tipo de razonamiento, como práctica de lectura, invita al lector a realizar los tres tipos de razonamientos (abducción, inducción, deducción); por tanto, el texto es un artificio construido a partir de niveles intrínsecos -lo lexical, lo sintáctico y lo semántico-y extrínsecos -debido a su naturaleza pragmática-.

Este tipo de lectura se hace posible en una variedad de textos; sin embargo, el autor se pregunta si la abducción se torna más promisoria en algunos géneros narrativos, como por ejemplo en las obras policíacas. De igual modo, señala que la abducción se constituye en un proceso científico, puesto que "mediante hipótesis y abducciones nuevas y más osadas, podemos descubrir nuevas verdades [...], sólo mediante ellas podemos ampliar nuestra visión de lo real y descubrir nuevos caminos de experiencia" (Vélez, 1996, p. 31).

En esta misma línea Ardila, considera que el texto literario tiene la cualidad de reunir una serie de códigos (lingüísticos, no lingüísticos e ideológicos, entre otros) que le exigen al lector adquirir una competencia para pasar de "lo literal a lo simbólico, de lo explícito a lo implícito" (2002, p. 947). Es decir, independiente del género literario, el lector debe estar en condiciones de participar en la construcción del sentido del texto o del "enunciado mismo".

Se pregunta cómo puede pasar un "lector de ficciones" del "uso del texto" -entendido como un ejercicio 
moralizante y descriptivo-a una lectura crítica que le permita referirse a las propuestas conceptuales y a las visiones de mundo que sugiere el enunciado del texto; además por el cómo hacer para que los estudiantes de la básica y del nivel medio desarrollen las competencias necesarias para una lectura comprensiva e interpretativa del texto ficcional.

Su propuesta se apoya en los planteamientos de Umberto Eco (1997) y Tardif (1997), quienes reconocen el diálogo entre los saberes del lector, el autor y el contexto de la obra. Con base en estos referentes, muestra algunos modelos de lectura susceptibles de convertirse en una "posible didáctica" de la lectura literaria: la lectura literal del texto, expuesta ampliamente por Van Dijk; la lectura abductiva, donde aparecen figuras como Umberto Eco y Sebeok; y una lectura simbólica del texto, apoyada en diversas ciencias y disciplinas como la hermenéutica filosófica, la antropología cultural, la fenomenología y la semiótica narrativa. En el primer modelo, el lector realiza procesos de generalización, construcción y categorización, entre otros; en el segundo, debe activar su capacidad de análisis, comparación, clasificación, asociación y explicación con el fin de construir hipótesis explicativas del sentido del texto; en el tercero, y último, debe alcanzar la comprensión del texto y realizar procesos de correlación y proyección inter y extratextuales.

Desde el punto de vista cognitivo, esta forma de proceder con el texto de ficción desarrolla habilidades particulares: análisis, comparación, clasificación, asociación y explicación. Asimismo, la hipótesis explicativa, al resolver el enigma, le permite al lector acceder al mundo posible del relato, el del autor, y su propio horizonte de expectativas como perceptor del texto. Por ello, el mundo posible construido por el lector debe entenderse como aquel "objeto cultural" que al surgir de una "realidad compleja" de la obra de ficción adquiere un valor simbólico.

A modo de conclusión, la autora señala que sus concepciones pretenden sugerir otros "modos diferentes de leer" los textos de ficción. Pues se trata de "una mirada tripartita" en donde la lectura literaria abarca aspectos formales y semánticos, además de procesos de comprensión e interpretación. Esto viabiliza el diseño de tareas y actividades de la clase de literatura, con la idea de que los estudiantes adquieran diversos tipos de conocimientos (declarativos, procedimentales, condicionales y procedimentales en diversos grados). Por ello, una didáctica de la lectura del texto literario es, desde tal perspectiva, "pertinente y apropiada" para estudiantes de primaria, bachillerato, y aún para sus maestros.
De manera semejante, para Vásquez (1995) la lectura abductiva no consiste en un conjunto de habilidades, tampoco un ejercicio para la decodificación de signos. Se constituye en una actividad de abducción; un ejercicio conjetural que le permite al lector lanzar hipótesis relacionadas con el sentido posible del texto, un proceso de permanente semiosis, una apuesta a las posibilidades de sentido.

Este juego de posibilidades, de acuerdo con Vásquez (2002a), se amplía cuando el maestro apoyado en la semiótica, la hermenéutica y la literatura promueve el dinamismo creador entre la escritura y la lectura. Mientras la primera es testimonial, pues hace parte de la tradición, en la segunda se actualiza, se apropia, se empieza a domeñar lo ajeno al convertir la lectura en un espacio para la libertad.

"La lectura en su relación
dialógica con la escritura
convierte al lector en copartícipe
del pacto enunciativo: un
explorador interesado en la
expansión del significado y el
sentido del texto; en suma, lo

motiva a producir un nuevo texto a partir de 1o "ajeno"."

La lectura en su relación dialógica con la escritura convierte al lector en copartícipe del pacto enunciativo: un explorador interesado en la expansión del significado y el sentido del texto; en suma, lo motiva a producir un nuevo texto a partir de lo "ajeno". Este proceso al estar motivado por la relación entre semiosis y hermenéutica le permite al lector aprender a mirar lo que los demás dan por visto. Esta perspectiva configura el punto de encuentro entre Jauss y Pierce. Mientras el primero propone una teoría de la recepción estética, basada en la fusión de horizontes (texto-contexto-lector), el segundo invita al lector a ingresar al laberinto de las indeterminaciones, al apoyarse en la semiosis o, lo que es lo mismo, en el carácter indicial del texto literario.

En última instancia, el trabajo permanente entre la lectura y la escritura, además de mejorar las estrategias de enseñanza y aprendizaje del maestro y su aprendiz, les permite crear nuevos horizontes de entendimiento. Una forma complementaria de dicho entendimiento se encuentra en el taller. Para Vásquez (2002b), el taller de literatura consiste en una mímesis, una imitación, un aprendizaje basado en un modelado en donde el aprendiz observa un patrón para ir en búsqueda de su propio estilo. 
De esta manera, para que el aprendizaje se produzca, el profesor debe convertirse en el artífice del modelado. Esto significa impulsar una práctica pedagógica donde el predominio de su palabra ceda a la lógica de la creación, al papel artesanal al cual pertenece el taller, pues se trata de un proceso de fabricación donde poiesis, aistesis, semiótica, hermenéutica y abducción se reúnen en un dialogismo expansivo ${ }^{2}$.

De manera analógica, para Cruz, hablar de lectura literaria significa reconocerla a partir de sus relaciones con la estética de la recepción. Su exposición comienza con tres interrogantes: “¿Qué es literatura?, ¿Qué implica la enseñanza de la lectura literaria?, y ¿Qué es enseñar a leer literatura?" (2007, p. 65). Su indagación le permite sustentar que la lectura literaria se reconoce como una práctica para el fortalecimiento de los procesos cognitivos de los estudiantes en sus procesos de formación académica y personal.

Sustenta lo anterior a partir del texto clásico de Wolfgang Iser El acto de leer. Teoría del efecto estético. Advierte que, si bien Iser no asume una postura pedagógica para explicar el efecto estético de una obra, se hace posible trasladar sus planteamientos a un enfoque fenomenológico para mostrar las relaciones entre la teoría literaria y la didáctica de la literatura.

Como se puede apreciar, se refiere al lugar que le otorga la "estética de la recepción" y la "teoría del efecto estético" al lector. En la primera, el lector se nombra con cierta frecuencia, en especial en la investigación en didáctica de la literatura; la segunda, otorga al lector un papel más decisivo. Por ello, su exposición se fundamenta en el lector, dado que una obra literaria adquiere vida a partir del momento en que es leída, pues de repente surge un mundo referencial inexistente hasta ese instante único del acto de la lectura.

En esta perspectiva, la obra literaria tiene dos tópicos, el artístico y el estético. El primero ha sido construido por el autor en su acto creador y el segundo se refiere a las relaciones del lector con el texto, acto de imaginación y comprensión. La obra, entonces, no termina con la última frase de su escritor, pues ella comienza a partir la recepción estética del lector.

De lo anterior surgen algunos elementos para la didáctica de la lectura: la obra artística promueve la construcción de conocimientos al permitirle al lector acercarse a una visión del mundo y recrear su "pensa-

2 En palabras de Jauss, precursor de la estética de la recepción, "la poiesis (creación), la aisthesis (conciencia estética y receptiva) y la catarsis (experiencia intersubjetiva), son tres principios de la comunicación literaria que le permiten al lector superar el carácter instrumental de la literatura" (1992, p. 15). miento narrativo". Asimismo, en toda obra literaria se movilizan dos dimensiones: las tradiciones, normas y convenciones que posee el lector y los enunciados de la obra literaria portadores de la tradición literaria que le precede y los procesos de intertextualidad; dimensiones que se constituyen en la base del universo referencial de todo acto de lectura comprensiva.

La presencia del lector tiene una relación directa con los enunciados del texto, pues ha sido pensada de manera premeditada por el autor. Esto quiere decir que el lector construye los significados del texto; por tanto, la tarea de la escuela consiste en posibilitar en los estudiantes la comprensión e interpretación de los enunciados que proyecta el texto literario.

Con todo y lo anterior, la teoría del efecto estético consiste en una propuesta "epistemológica y metodológica" que le permite al maestro de literatura romper paradigmas por dos razones fundamentales: el texto literario reclama la presencia de un "lector ideal", quien tiene la posibilidad de moverse entre el horizonte de sentido del texto y su punto de vista; y la lectura es, ante todo, un "proceso de transformación", "una experiencia admirable" que se percibe cuando el lector siente como si llevara una vida distinta, como si fuera "otra persona", gracias al efecto transformador del acto lector.

En síntesis, para la mayoría de autores abordados en este apartado una apuesta por la didáctica de la lectura literaria exige la asunción de un enfoque metodológico de corte hermenéutico como una posibilidad de comprender el texto literario alejado de los modelos inmanentistas y cientificistas que casi siempre han dominado el horizonte de la comprensión y de la interpretación textual. Una lectura literaria, en clave hermenéutica, no configura un método invariable para la interpretación de textos sino una actitud para replantear las propuestas de lectura de corte tradicional -las cuales, en su afán por controlar el sentido del texto, recurren a posturas rígidas que ponen en duda el alcance y la pertinencia de los mismos-. Para la filosofía de corte fenomenológico y hermenéutico se tiene claro que el sentido del texto siempre se encuentra en movimiento, se construye y se adapta a los procesos sociohistóricos y, por esta razón, la comprensión siempre estará condicionada por el contexto e historia del presente de la lectura y por las competencias culturales de sujetos históricos que aborden la obra literaria con un universo referencial específico ${ }^{3}$.

3 A propósito, se considera pertinente recordar que, desde la hermenéutica de Gadamer (2005), el intérprete no puede situarse por fuera de su precomprensión o de sus prejuicios: de su mundo o su propio horizonte, conformado por su lenguaje, su cultura y su historia. Interpretar consiste en el 


\section{La didáctica de la literatura en el currículo}

Ubicados ahora en el plano de una concepción curricular de la didáctica de la literatura, Pérez se muestra de acuerdo con la existencia de "un núcleo curricular común para el país" (2004, pp. 67-68) que, sin obstaculizar los criterios del Proyecto Educativo Institucional (PEI) de la escuela, incentive la equidad, el dominio de saberes y competencias, independiente del lugar geográfico donde tenga lugar dicho proyecto. Esta visión contribuye con el desarrollo cultural de los estudiantes, los acerca al conocimiento y dominio de los códigos culturales, universales y locales y les permite participar en la construcción de escenarios pedagógicos y comunicativos para el diálogo respetuoso.

Apoyado en la teoría de Vygotski, reconoce la tensión entre el desarrollo orgánico del individuo y la cultura. Por ello, defiende la existencia, entre otros, de un "núcleo común, conformado por los códigos culturales y sociales, saberes y saberes hacer, visiones de mundo" (Pérez, 2004, p. 70). Estos códigos en el plan de estudios son los comunicativos o semióticos y permiten darle sentido y significado al mundo que rodea al individuo.

Así las cosas, su propuesta consiste en "la configuración de secuencias didácticas orientadas a la inserción de los estudiantes en prácticas discursivas a través del trabajo sobre los géneros" (Pérez, 2004 , p. 72). La idea de géneros se inspira en la teoría de Bajtín, quien los considera pretextos de comunicación cuando se entienden como prácticas sociodiscursivas. De las cinco modalidades de secuencia -argumentativa, descriptiva, explicativa, dialogal y narrativa- el autor muestra las posibilidades de la última en el contexto de un escenario de lectura y escritura vivenciado por estudiantes de quinto grado.

Con el apoyo del maestro del curso, los estudiantes elaboran una antología de cuentos que les permite movilizar habilidades particulares: la comprensión, la explicación, la producción y la interpretación, las cuales se hayan determinadas por el género y las prácticas sociodiscursivas que de él se derivan.

A pesar de que Pérez no presenta de manera explícita una conclusión, se debe reconocer que sus

encuentro entre el horizonte histórico de la obray el horizonte del hermeneuta, con lo cual se confirma y exalta la figura del intérprete como sujeto histórico fundamental en el proceso de interpretación textual, sin el cual el proceso hermenéutico perdería todo sentido y legitimidad. referencias a Bajtín motivan a una búsqueda de otras fuentes que amplíen tal influencia en los enfoques curriculares colombianos con énfasis en la didáctica de la literatura. En esta perspectiva, se ubican gran parte de las investigaciones de Fabio Jurado, Gloria Rincón, Alfonso Cárdenas y de otros docentes investigadores del país adscritos a la Red Nacional para la Transformación de la Formación Docente en Lenguaje.

Por ejemplo, Fabio Jurado (1994) señala que en Colombia y en la mayoría de los países latinoamericanos la obra de Bajtín y Voloshinov comienza a difundirse en la década del ochenta, aunque en los setenta algunas revistas colombianas publican temas bajtinianos. En efecto, para Jurado existen tres discursos o prácticas sociodiscursivas que sintetizan un enfoque acerca de la lengua y la literatura en Colombia: los programas curriculares, los libros de texto y la clase. La mayoría de estos discursos le dicen al maestro qué debe "saber" y "hacer" el estudiante de acuerdo con su grado de escolaridad; situación que fragmenta el conocimiento y se homogeniza a este último al mostrarle modelos del buen "escribir" y "hablar".

En esta visión el hablante y la lengua tienen como punto de partida la crítica que Bajtín y Voloshinov presentan al "subjetivismo individualista" y el "objetivismo abstracto". La primera corriente considera la lengua como un producto estático, que al ser formalizado por la lingüística hace posible su enseñanza. En la segunda, la lengua es superior al sujeto pues éste debe someterse a las reglas del sistema lingüístico y la comunidad lingüística, ambas encargadas de normalizar su funcionamiento.

De manera contraria, Jurado expresa que para Bajtín la palabra es "dialogismo" al hacer parte de actuaciones y vivencias del hablante; consiste en "coparticipación entre un hablante y su interlocutor" (1994, p. 7); reconoce la presencia de un destinatario; interactúa "desde el otro y la colectividad para actualizar el sentido en construcción" (p. 8). En suma, su presencia dialógica significa reconocerla para la interpretación del pensamiento convergente y divergente.

En conclusión, el dialogismo sociodiscursivo de diversos géneros, y en particular de la lectura literaria, cuestiona las clasificaciones estandarizadas de obras literarias (movimientos, escuelas, períodos, géneros); los exámenes memorísticos que, al seguir el "libro de texto" o inspirados en dicho enfoque, normalizan la enseñanza compensatoria; el canon que deja de lado obras de la cultura popular oral y escrita, entre otras expresiones artísticas a las que deben acceder los estudiantes. 
De manera similar, Álvarez, Rodas y Piedrahíta (2005) expresan que a la didáctica de la literatura le corresponde articular y estudiar particulares dimensiones y campos del ámbito escolar: las intenciones de quienes diseñan el currículo en esta área, las concepciones de estudiante que se derivan de dichas propuestas, las nociones de aprendizaje y las situaciones que potencian u obstaculizan el desarrollo del Proyecto Educativo Institucional (PEI) en atención al currículo y los programas de área.

En este contexto, la didáctica de la literatura en Colombia ha focalizado sus reflexiones en los procesos de la enseñanza y del aprendizaje de la lengua materna o extranjera. Este anclaje no le ha permitido ser comprendida como "un fenómeno estético y literario que tiene sus propias reglas" (Álvarez, Rodas y Piedrahíta, 2005, p. 50). Unido a lo anterior, los diversos géneros literarios (poesía, cuento, novela, drama) tampoco han sido estudiados en atención a su complejidad. Así, cuando se analiza la historia de la enseñanza de la literatura se puede observar cómo en la década de los años noventa del siglo XX el maestro se pregunta por el lugar del canon en la clase de literatura: ¿qué leer, por qué, para qué y cómo? Estos interrogantes lo llevan a reconocer al estudiante en otros ámbitos y dimensiones. De algún modo, lo convocan a retomar la figura del lector implícito y cómplice creado por Cortázar en su obra hipertextual Rayuela. En dicha novela el narrador sugiere una didáctica de la "dificultad", entendida como mediación estética. Aquí el lector debe trasegar por la estructura textual para ir descubriendo los laberintos del tejido estético y convertir la palabra en un "acontecimiento discursivo".

En este contexto, la lectura se constituye en una "experiencia" en la cual el estudiante y el maestro olfatean la obra en busca de nuevas pistas para su comprensión. Este enfoque hace explícita la necesidad de "privilegiar las actitudes investigativas" del docente y su relación con las actividades extracurriculares. De igual modo, insta al maestro de literatura para que convierta su práctica pedagógica en un espacio de "saber". Actuar en consecuencia significa superar las prácticas de enseñanza interesadas en "gramaticalizar, semantizar y moralizar" la relación entre el lector y el texto.

\section{Estrategias de lectura y escritura literaria}

En palabras de Vargas, "el taller de escritura creativa en el aula se debe convertir en el recurso pedagógico por excelencia, en una herramienta insustituible sobre la cual se soporta una didáctica de la literatura emancipadora" (2005, p. 65). El primer eslabón de su propuesta tiene como punto de partida la premisa de que "la didáctica de la literatura es una disciplina crítica y emancipadora en construcción" (p. 60) que entiende la competencia literaria en una doble dimensión: como "una capacidad para la producción de estructuras poéticas" y de la cual se derivan unos "efectos". Así, el taller de escritura creativa se entiende como un espacio real de acercamiento al conocimiento conceptual de la literatura y la creación de textos con sentido estético. En este enfoque metodológico, la lectura trasciende la pregunta de qué dice el texto al avanzar en la discusión de los géneros, las teorías que le dan un mayor esclarecimiento, sin olvidar el goce estético.

En esta misma dirección, Gómez señala que un taller de escritura comienza cuando el maestro de literatura supera el prejuicio de que los manuales enseñan este oficio, pues "nadie puede enseñar a leer, escribir o investigar" (2005, p. 85). Con esta afirmación pretende mostrar que la escritura y la investigación son procesos de pensamiento complejos en los que cada sujeto se involucra en forma distinta. La tarea del maestro consiste, entonces, en enseñarles a los estudiantes a utilizar herramientas de argumentación para mejorar los procesos de pensamiento relacionados con la composición y la corrección de un texto. Este proceder le permite al estudiante tomar conciencia de la estructura lógicodiscursiva del texto en construcción. Esta idea del taller de escritura como herramienta se sustenta en 
los planteamientos de García Márquez, quien señala que los mejores enseñantes del misterioso arte de la creación escrita son "los buenos libros".

Por consiguiente, si la relación entre lectura y escritura es directa, el maestro debe hacerse consciente de que la corrección del texto debe fundamentarse en los criterios generales que rigen a estas dos competencias comunicativas: corregir, de una parte, aspectos formales como la puntuación, la lógica en el proceso argumentativo, el tono, entre otros, y, de otro lado, comprender que darle al texto "el sentido estético" anhelado se convierte en una tarea de largo aliento -pues la asunción de un "estilo" significa "ampliar los caminos y la visión del aprendiz sugiriendo libros", "buenos libros" en palabras de García Márquez, citado por Gómez (p. 89)-.

A modo de conclusión, Gómez dice que "el taller de escritura como estrategia didáctica es un punto de llegada" (p. 90), en tanto se inscribe en un proceso de preparación. Un taller con estas características solamente puede ser adelantado por un maestro "apasionado por la didáctica y por la escritura" (p. 91). Esta didáctica incluye el arte de enseñar y al arte de escribir. El desconocimiento de alguna de estas artes podría mostrar que no han sido vividas por el maestro; por tanto, sería "imposible enseñar algo, si no se ha puesto de manifiesto lo que pretenden exponer" (p. 93).

\section{La didáctica de la literatura en la perspectiva de la formación de un maestro investigador}

De acuerdo con Gómez de González, González y Rincón (1997), la teoría literaria ha ocupado en los últimos años un lugar importante en Colombia, al igual que los estudios literarios. Pero no ocurre lo mismo con la "producción de materiales didácticos" para la promoción de una práctica pedagógica que acerque a los estudiantes a la pasión por la literatura y el placer por el texto. Por ello, se proponen desarrollar una investigación que integre lo teórico-práctico al "quehacer literario", con la idea de hacer evidentes modelos pedagógicos que reconozcan la diversidad de actores y de géneros, los derechos del lector, la infinitud de la obra literaria, la polifonía, el humor, la risa y la intertextualidad, entre otras expresiones asociadas y propias del texto literario. En su marco teórico retoman el concepto de texto de Lotman y de Bajtín, quienes expresan que el texto debe ser comprendido a partir de sus dimensiones y entendido como un proceso de la comunicación literaria. Una de estas dimensiones, la estética comunicativa, incluye las relaciones entre el autor (biografía, entrevistas, diarios), el texto (relaciones con el autor, el contexto de la obra, proceso de recepción) y el lector (situación social, conocimientos previos, experiencia de lectura, entre otros factores).

Esta opción didáctica se propone comprender tres dimensiones: las relaciones del lector con el texto como un proceso productivo, donde interviene la comunicación literaria, en tanto proceso de recepción; la presencia de diversas disciplinas interesadas en comprender la recepción estética; y los referentes conceptuales del docente orientados a fortalecer su propuesta pedagógica. En suma, tal apuesta didáctica exige comprender la recepción estética de la obra como un proceso de aprendizaje.

Por ello, la interacción pedagógica (o comunicativa) se asume en términos habermasianos. Así, la "comunicación literaria en el aula de clase" debe ser comprendida a partir de su efecto emancipador y como una invitación al diálogo y la reflexión. Esto le permite al maestro, al lector, al texto y al autor ser comprendidos en su dimensión histórica y ser reconocidos como sujetos creativos, dispuestos al diálogo, a escuchar las voces del texto, sus silencios, a fusionar su horizonte de expectativas previas con las nuevas para alcanzar la comprensión interhumana.

De este enfoque disciplinar y didáctico se considera pertinente rescatar de la didáctica: su posibilidad como acontecimiento dialógico -debido a la comunicación del maestro y el estudiante con las voces del texto literario y su posterior socialización-, su condición multidimensional -es decir, el carácter problémico e histórico del texto, en cuyo interior se insinúa un enigma que el lector debe resolver en el contexto de la pregunta de dónde ha surgido- y su posibilidad en la recepción estética de la obra-que, unida a su "comprensión dialógica", sugiere la correspondencia entre los modos de lectura de los estudiantes y los objetivos de aprendizaje-. En suma, se trata de una didáctica de la indagación que reconoce el carácter social e histórico del texto literario, el lector, el maestro y el grupo de estudiantes dispuestos a la "conversación" interhumana.

En efecto, la formación de un maestro de literatura como investigador de su práctica pedagógica se constituye en una tarea de largo aliento en la escuela colombiana. Esta idea la confirman Arboleda, Castañeda, Cifuentes, Rondón y Rosas, quienes se propusieron adelantar un proceso de investigación cualitativa de corte etnográfico y abductivo con un grupo de maestros en ejercicio adscritos a una Maestría en lectura y escritura en educación. 
“...la formación de un maestro de literatura como investigador de su práctica pedagógica se constituye en una tarea de largo aliento en la escuela colombiana."

Dado que su investigación pretende identificar la presencia de la literatura en la escuela (cursiva de los autores) y fortalecer el saber didáctico en dichos maestros formulan, entre otras, una pregunta básica: “¿Cómo avanzar en el entrenamiento de los estudiantes [de la maestría] como investigadores, dadas las carencias o serias deficiencias en esta formación a nivel del pregrado?" (Arboleda et al., 1999, p. 45). Este interrogante los insta a formular una estrategia estructurada en cuatro ejes: creación de líneas de investigación; formulación de proyectos en la escuela, liderados por los maestrantes en calidad de coinvestigadores; estructuración de una propuesta de formación en investigación; y realización de talleres de lectura a partir de la teoría abductiva, entendida como práctica social y estética.

Dichos ejes promueven un perfil específico para un maestro investigador: a quien investiga lo mueven las incertidumbres, las hipótesis, los indicios y las preguntas. La aventura de la investigación consiste en superar obstáculos, aventurarse, arriesgarse a dejarse sorprender por lo inasible. Además, allí el humor es tan fundamental como la autocrítica. El primero se hace pertinente al comienzo de la investigación, en especial, cuando los caminos parecen difusos y/o errados; la segunda, se constituye en acicate donde la práctica reflexiva del docente encuentra la posibilidad de construir nuevos conocimientos.

A propósito de la capacidad de autocrítica del maestro, surge como un hecho sorprendente el escaso desarrollo de "un conocimiento sobre la didáctica de la literatura en la escuela; en consecuencia no era viable elaborar un estado del arte" (Arboleda et al., 1999, p. 69). En su búsqueda, los autores citados encuentran información en relación con los géneros literarios, la literatura infantil, las estrategias didácticas; en otras palabras, aportes fragmentarios que no tienen una relación directa con el lugar de la didáctica de la literatura en la escuela. Esta limitante se supera cuando el equipo docente realiza nuevas búsquedas a partir de en la definición de campos semánticos afines a la didáctica de la literatura: adelantar una fenomenología y epistemología de conceptos como didáctica y literatura, entre otros.
A modo de conclusión, los autores señalan que la investigación cualitativa de corte etnográfico y abductivo adquiere coherencia al demostrar el lugar de dichas teorías en los procesos de investigación en el aula. Disciplinas como la didáctica de la literatura (cursiva del texto) se convierten en umbrales que pueden superar su anonimato cuando logran un nivel de rigurosidad y de sistematicidad. Un ejemplo de esta búsqueda por el estatus epistemológico de esta didáctica se puede inferir de los principios pedagógicos que los autores presentan para los interesados en formarse como investigadores reflexivos.

La siguiente relación de algunos de tales principios pedagógicos permiten el cierre del presente apartado: aprender del error, formar equipos de trabajo, aprender haciendo, aprender reflexionando críticamente, reconocer que en la formación en investigación el maestro enfrenta diversas dificultades: la insuficiencia para articular la teoría y la práctica, la búsqueda de certezas en lugar de aprovechar el valor heurístico de la incertidumbre y la escritura apresurada que obstaculiza el análisis detenido de la información (miedo a descubrir el error) y que pondera ciertas interpretaciones basadas en la generalización de la experiencia y llevan al olvido del sentido de la subjetivación, entre otros.

\section{Conclusiones}

Un repaso por los autores, las investigaciones y los enfoques metodológicos abordados en este texto permite comprender la necesidad de transformar la clase de literatura en un espacio para la investigación donde el saber literario y el saber didáctico dialoguen a partir de las preguntas generadas por el texto literario que son, al mismo tiempo, las aspiraciones y las dificultades propias del ser humano dispuesto a la conversación y a la comprensión interhumana.

"Un repaso por los autores, las investigaciones y los enfoques metodológicos abordados en este texto permite comprender la necesidad de transformar la clase de literatura en un espacio para la investigación donde el saber literario y el saber didáctico dialoguen a partir de las preguntas generadas por el texto literario..." 
Cada autor, investigación y enfoque relacionado con la didáctica de la literatura insta al maestro a asumir el rol de investigador en el aula de clase como una alternativa para conducir con responsabilidad social y estética la formación literaria de los estudiantes. Asimismo, los tres tópicos estructurantes de este texto, la didáctica de la lectura literaria, la literatura en el currículo, unido a sus estrategias de lectura y escritura, y la investigación en didáctica de la literatura, se encaminan hacia la búsqueda de la "abducción" como un punto de articulación entre el saber literario y el saber didáctico del maestro en ejercicio y en formación.

Desde esta perspectiva se concibe la hermenéutica y la abducción como dos enfoques teóricos pertinentes, creativos y significativos para la construcción de una didáctica de la lectura literaria, en la medida que asumen el texto literario no como objeto per se sino como obra humana donde su creador (el autor) y lo creado (el texto) dialogan con un lector dispuesto a una búsqueda de significados y una actitud flexible y atenta para hallar el sentido y, tal vez, así llegar a la comprensión hermenéutica y abductiva del texto.

Por otro lado, estos hallazgos señalan que al interior de los estudios en didáctica de la literatura es dable encontrar tres temas macro que, si bien se asumen de manera "interrelacionada" tanto en el ámbito escolar como universitario, se considera importante analizarlos a partir de la visión histórica, epistemológica y didáctica que los sustenta. Hacerlo de esta manera, le permite al maestro en ejercicio y al formador de maestros de literatura tomar conciencia de la opción social y política en que se inscribe su propuesta didáctica.

El balance que arroja este recorrido por algunas concepciones de la didáctica de la literatura en el país hace evidente que están dadas las condiciones para la formación de lectores críticos del texto literario. Para ello, el maestro colombiano debe asumir la posibilidad de construir e implementar en el aula una didáctica de la lectura literaria que trascienda el modelo alfabetizador hacia otro más innovador y significativo centrado en la comprensión e interpretación crítica de los textos literarios. Por tanto, la puesta en escena de dicha didáctica podría ampararse en la teoría de la abducción y la hermenéutica literaria para enriquecer el horizonte expectativas de los maestros y los estudiantes en su interacción comunicativa con los textos de la tradición regional, nacional e universal.

Es perentorio promover en maestros en ejercicio y en formación una reflexión en torno de la didáctica de la literatura. Esto exige acercarlos a los marcos teóricos que sustentan los procesos de lectura y de escritura con propósitos estéticos y comunicativos en general. Por otro lado, es alentador saber que en Colombia existe una preocupación por la didáctica de la lectura literaria y las estrategias de lectura y escritura creativa. Sin embargo, sigue pendiente la realización de proyectos de investigación en didáctica de la literatura que le muestren al maestro las posibilidades que tiene esta disciplina reconstructiva de fortalecer su saber didácticoy disciplinar. Hacerlo de esta manera, se convierte en un aliciente para fortalecer su capacidad de indagación creativa en el aula.

En conclusión, para la mayoría de los autores presentados, la didáctica de la literatura se entiende como una estrategia de lectura, para otros es un ejercicio de creación y hay quienes la ubican como un detonador cognitivo y/o un método para la investigación en el aula. Esta última opción motiva a los autores del presente artículo a seguir analizando nuestra pregunta de investigación: ¿cómo traducir la recepción estética de la obra literaria y la teoría de la abducción para formar maestros investigadores en el contexto de la didáctica de la literatura en la educación superior?

Finalmente, se ha de advertir que estos autores, investigaciones y enfoques, y seguramente otras figuras destacadas del panorama nacional, harán parte de una segunda revisión relacionada con otras concepciones de la didáctica de la literatura en Colombia.

\section{“...para la mayoría de los autores presentados, la didáctica de la literatura se entiende como una estrategia de lectura, para otros es un ejercicio de creación y hay quienes la ubican como un detonador cognitivo y/o un método para la investigación en el aula.”}




\section{Bibliografía}

Álvarez Correa, A.; Rodas Montoya, J. y Piedrahita Lara, F. (2005), "Enseñabilidad de la literatura en el ámbito escolar”, en: Vásquez Rodríguez, F. (comp.), pp. 43-58.

Arboleda, M., et al. (1999), "Rastreo Bibliográfico sobre la didáctica de la literatura en la escuela”, en: Vásquez, F. (comp.), pp. 43-122.

Ardila, C. (2002), "Hermenéutica literaria: Tres estrategias para la interpretación de textos narrativos”, en: Memorias del XX Congreso Nacional de Lingüística, Literatura y Semiótica, Cali, Universidad del Valle, pp. 940-952.

Cárdenas Páez, A. (1998a), Argumentación, interpretación y competencias de lenguaje, disponible en: http:// www.pedagogica.edu.co:8080/w3/storage/folios/ articulos/folios11_08arti.pdf, recuperado: 13 de noviembre de 2008.

Cárdenas Páez, A. (1998b), Pensar bien para leer mejor, disponible en: http://www.ascun.org.co/eventos/ lectoescritura/alfonsocardenas.pdf, recuperado: 13 de noviembre de 2008

Cárdenas Páez, A. (2000), Implicación, inferencias y competencias de interpretación, disponible en: http:// www.pedagogica.edu.co:8080/w3/storage/folios/ articulos/fol13_09arti.pdf, recuperado: 13 de noviembre de 2008

Cruz Calvo, M. (2007), “Leer literatura...Enseñar literatura. De la estética de la recepción a la didáctica de la literatura (aportes preliminares). Perspectivas sobre la enseñanza de la lengua materna, las lenguas y la literatura", en: Didáctica de la literatura, Cali, Universidad del Valle, pp. 65-76.

Eco, U. (1997), Seis paseos por los bosques narrativos, Barcelona, Lumen.

Gadamer, H. G. (2005), Verdad y Método I, Salamanca, Sígueme.

Gómez de González, B.; González Martínez, H. y Rincón Cubides, G. (1997), La cultura popular en Los Funerales de la Mamá Grande, Bogotá, Universidad Pedagógica Nacional.

Gómez Moreno, W. (2005), "El taller de escritura”, en: Fernando Vásquez Rodríguez (Comp.), pp. 81-93.

Iser, W. (1987), El acto de leer. Teoría del efecto estético, Madrid, Taurus.

Jauss, H. R. (1992), Experiencia estética y hermenéutica literaria. Ensayos en el campo de la experiencia estética, Barcelona, Taurus Humanidades.
Jurado, F. (2000), “Las aducciones de los profesores como lectores. A propósito de una lectura de Una mujer amaestrada, de Juan José Arreola", en: Enunciación, núm. 4-5.

Jurado, F. y Bustamante, G. (1995), Lectura, incertidumbre y escritura, Bogotá, Delfín Limitada.

Jurado, F. (1994), Bajtín-Voloshinov. Para el estudio del lenguaje y la literatura en la Educación Básica, disponible en: www.redalyc.uaemex.mx/redalyc/pdf, recuperado: 28 de agosto de 2009.

Pérez Abril, M. (2004), "Elementos para pensar un plan de estudios en el campo del lenguaje y la literatura", en: Redlecturas. Un espacio para la escritura y el diálogo razonado. Nodo de Lenguaje de Antioquia, Medellín, Zuluaga.

Ricoeur, P. (1996), Teoría de la narración, México, Siglo XXI.

Tardif, J. (1997), “La evaluación del saber-leer: un asunto más de competencia que de actuación", en: La lectura, Cali, Universidad del Valle.

Vargas Celemín, L. (2005), "La enseñanza de la literatura o el regreso a Ítaca”, en: Vásquez Rodríguez, F. (comp.), pp. 59-70.

Vásquez Rodríguez, F. (1995), “Lectura, abducción, escritura y reconocimiento", en: Jurado, F. y Bustamante, G. (comp.) Los procesos de lectura. Hacia la producción interactiva de sentidos, Bogotá, Mesa Redonda, Magisterio, pp. 142-147.

Vásquez Rodríguez, F. (1999), Didáctica de la literatura en la escuela. Bogotá, Pontificia Universidad Javeriana, Facultad de Educación.

Vásquez Rodríguez, F. (2002a), "La semiosis-hermenéutica. Una propuesta de crítica literaria”, en: La cultura como texto. Lectura, semiótica y educación, Bogotá, Pontificia Universidad Javeriana, Facultad de Educación, pp. 96-110.

Vásquez Rodríguez, F. (2002b), “Semiótica del taller”, en: La cultura como texto. Lectura, semiótica y educación, Bogotá, Pontificia Universidad Javeriana, Facultad de Educación, pp. 185-188.

Vásquez, F. (comp.) (1999), Didáctica de la literatura en la escuela, Bogotá, Pontificia Universidad Javeriana, Facultad de Educación.

Vásquez Rodríguez, F. (Comp.) (2005), La didáctica de la literatura-Estado de la discusión en Colombia, Bogotá, s/e. Vélez Upegui, M. (1996), "Leer: o el tránsito de la epifanía a la abducción”, en: Segundo Encuentro de Egresados y Estudiantes de Educación Españoly Literatura, Medellín, Universidad de Antioquia y Artes y gráficas Júpiter. 


\section{Sistematización de experiencias}

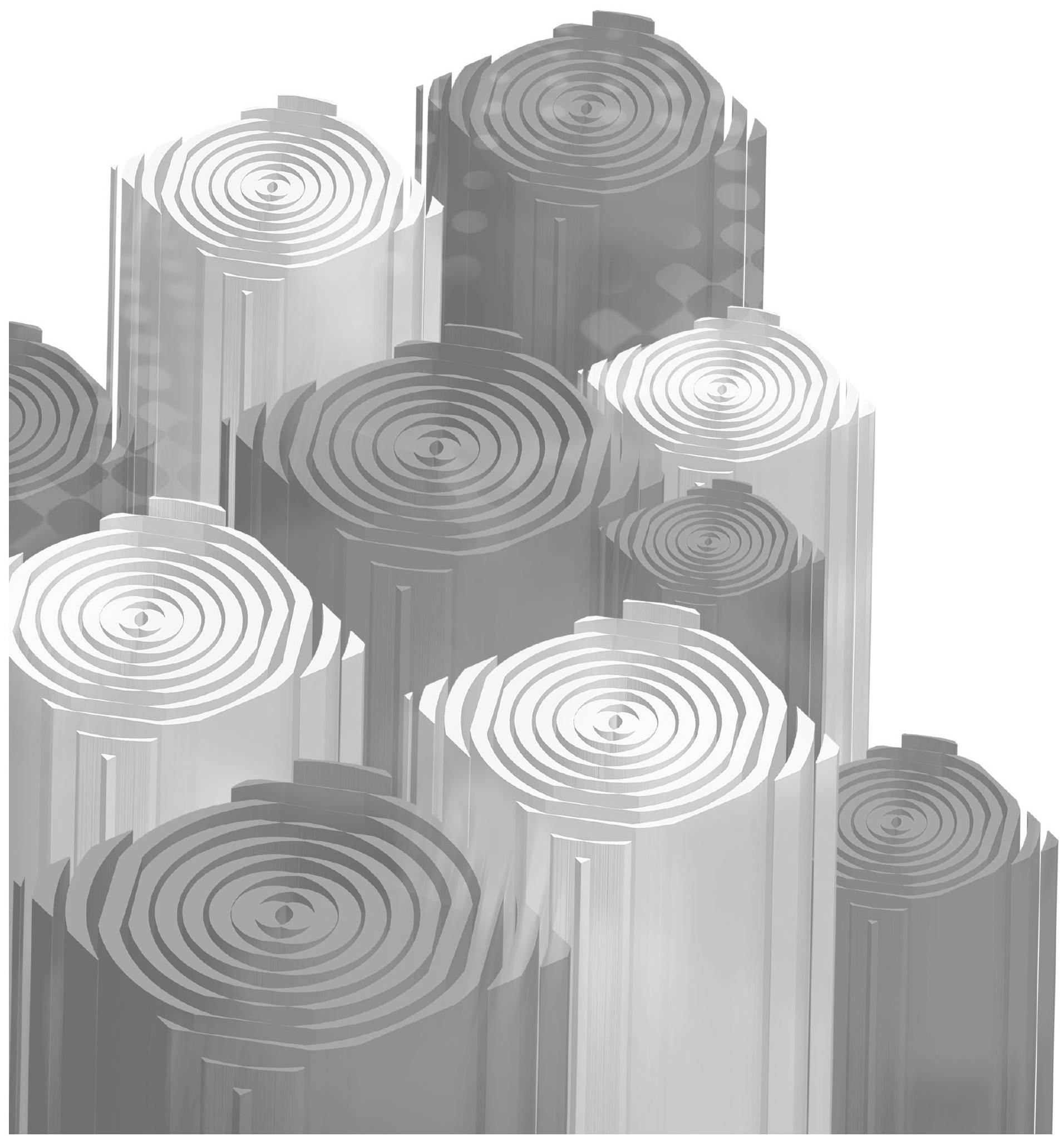




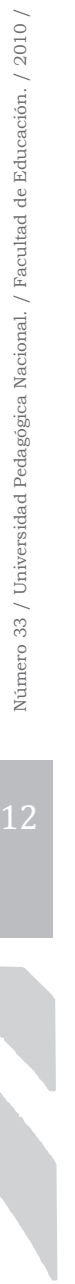

